\title{
Stage effect of chronic kidney disease in erectile function
}

\author{
Márcio Rodrigues Costa ${ }^{1}$, Viviane Campos Ponciano ${ }^{2}$, Théo Rodrigues Costa ${ }^{3}$, Caio Pereira Gomes ${ }^{1}$, Enio \\ Chaves de Oliveira ${ }^{1}$ \\ ${ }^{1}$ Escola Médica da Universidade Federal de Goiás, GO Brasil; ${ }^{2}$ Mercy Holy House, Goiânia, GO, Brasil; \\ ${ }^{3}$ Hospital Geral de Goiânia Doutor Alberto Rassi, GO, Brasil
}

\section{ABSTRACT}

Purpose: The study aims to assess the influence of the stage of chronic kidney disease and glomerular filtration rate on prevalence and degree of erectile dysfunction.

Materials and Methods: This transversal study, conducted from May 2013 to December 2015, included patients with chronic kidney disease in conservative treatment, stages III/IV/V. Erectile dysfunction was evaluated by the International Index of Erectile Function. Data classically associated with erectile dysfunction were obtained by medical record review. Erectile dysfunction, degree of erectile dysfunction, and other main variables associated with erectile dysfunction were compared between patients with chronic kidney disease on conservative treatment stages III versus IV/V using the Chi-square test. The relationship between score of the International Index of Erectile Dysfunction and glomerular filtration rate was established by Pearson correlation coefficient.

Results: Two hundred and forty five patients with chronic kidney disease in conservative treatment participated of the study. The prevalence of erectile dysfunction in patients with chronic kidney disease in stages IV/V was greater than in stage III. Glomerular filtration rate positively correlated with score of the International Index of Erectile Dysfunction.

Conclusions: The study suggests that chronic kidney disease progression (glomerular filtration rate decrease and advance in chronic kidney disease stages) worsen erectile function. Hypothetically, diagnosis and treatment of erectile dysfunction may be anticipated with the analysis of chronic kidney disease progression.

\section{ARTICLE INFO}

\section{Keywords:}

Renal Insufficiency, Chronic; Kidney Failure, Chronic; Erectile

Dysfunction

Int Braz J Urol. 2018; 44: 132-40

Submitted for publication:

April 09, 2017

\section{Accepted after revision:}

July 29, 2017

Published as Ahead of Print: October 16, 2017

\section{INTRODUCTION}

Erectile dysfunction (ED) is a persistent inability to attain and/or maintain an erection sufficient to satisfactory sexual performance (1). This sexual disorder should be promptly investigated and treated because it may impair quality of life and health status of its carriers (1-3). In ED investigation, chronic kidney disease (CKD) is a frequent disorder found as a possible cause, but it can also be a consequence $(4,5)$. Curiously, ED seems to be forgotten and sometimes neglected in that health condition (6).

Many studies have analyzed ED in patients with CKD. The ED prevalence found in these works was usually high (5-10). Age, depression, diabetes mellitus, cardiovascular diseases, duration of CKD, being married, being employed, and not using some antihypertensive drugs (angiotensin-converting enzyme inhibitors) were factors in- 
volved with ED in patients with CKD (5-10).

Some studies specifically evaluated patients with ED and chronic kidney disease on conservative treatment (CKDCT) (9-14). In these patients, ED prevalence found was variable, but usually high. Among risk factors for ED, diabetes mellitus and time of CKD stood out (8). The role of CKD stages and the glomerular filtration rate (GFR) as risk factors on ED aroused attention because no unanimous response was found. Some studies show association of ED with GFR and CKD stages, others only in specific population Groups or do not establish this relationship in any way (8, 10, 11, 15-18). Therefore, our study evaluated the influence of CKD stages and GFR on the ED prevalence and degree to clarify this point.

\section{MATERIALS AND METHODS}

This transversal study, conducted from May 2013 to December 2015, was approved (registration no. 090/2011) by the Ethics Committee of the Federal University of Goiás Clinical Hospital, in accordance with Helsinki Declaration of 1975 revised in 1983.

For practical purposes, CKDCT was defined as structural or functional abnormalities of the kidney, present for more than 3 months, with health implications, in patients who did not receive renal replacement therapy, dialysis, or renal transplantation.

Male patients, volunteers, heterosexuals, carriers of CKDCT, from two hospitals in the city of Goiânia (Brazil), without cognitive or communication impairment and that signed an informed consent form were included in this study. The patients were classified into CKD stages according to the criteria of the Kidney Disease Outcomes Quality Initiative (2012) (19) (Table-1). Some descriptive data of these patients, presented in this work, were submitted in another research (10).

Patients with creatinine clearance, estimated by the Cockcroft-Gault equation (20), greater than or equal to $60 \mathrm{~mL} / \mathrm{min} / 1.73 \mathrm{~m}^{2}$, or without data to estimate it (weight, age, or serum creatinine value), were excluded.

Patients were individually approached, before their scheduled medical visit, in nephrology services, previously cited. They received a brief explanation about the research and were instructed to read and interpret questions about erectile function of the International Index of Erectile Function (IIEF). Life habits, sociodemographic characteristics, clinical and laboratory data were obtained from medical records review made by five researchers.

The variables evaluated were: age, marital status, body mass index, systemic arterial hypertension, diabetes mellitus, coronary artery disease, congestive heart failure, time of $\mathrm{CKD}$, smoking, pack years of smoking, alcohol use, antihypertensive numbers, antidepressants and anxiolytics use, hematocrit, cholesterol, high density lipid cholesterol, low density lipid cholesterol, and triglycerides.

ED was assessed by erectile function domain of the IIEF (questions numbers 1 to 5 and 15) (21). According to answers of the questions, patients obtained scores of 1 to 30. Patients were classified according to their scores as follows: no

Table 1 - Chronic Kidney Diseases stages.

\begin{tabular}{lc}
\hline Stages & Glomerular filtration Rate $\left(\mathbf{m L} / \mathbf{m i n} / \mathbf{m}^{2}\right)$ \\
\hline I & $>90$ \\
II & $89-60$ \\
III a & $59-45$ \\
III b & $44-30$ \\
IV & $29-15$ \\
V & $<15$ \\
\hline
\end{tabular}

In the absence of evidence of kidney damage, stage I and II do not fulfill the criteria for Chronic Kidney Disease. 
ED (score 25 to 30); mild ED (score 19-24); mild to moderate ED (score 13 to 18); moderate ED (score 7-12), and severe ED (score 1-6).

Data were tabulated in Microsoft ${ }^{\circledR}$ Excel 2007 and analyzed by Statistical Package for Social Sciences for Windows 16. Descriptive analysis was done for ED and its categories (according to IIEF), life habits, sociodemographic characteristics, and clinical and laboratory data. Categorical variables were assessed by ED proportion in each category and continuous variables by ED proportion in categories created to facilitate interpretation of results. ED prevalence, ED degrees, and each categorical variable of patients with CKDCT stage III were compared with their corresponding stage IV/V, using Chi-square test. Severe ED was compared with other ED degrees in patients in stage III using the previous test. Stage IV/V patients were grouped and similar comparison was done. $\mathrm{P}$ equal or less than 0.05 was considered statistically significant. Relationship between IIEF score and GFR was analyzed by Pearson correlation coefficient.

\section{RESULTS}

The study assessed 338 patients with CKDCT, 245 (72.49\%) patients were included and $93(27.51 \%)$ excluded. Mean age was $63.36 \pm 13.74$, $67.16 \pm 14.43$, and $66.52 \pm 12.27$ years in stages III, IV, and V, respectively. Creatinine clearance (estimated) means were $33.34,23.07$, and $12.14 \mathrm{~mL} /$ $\mathrm{min} / 1.73 \mathrm{~m}^{2}$ in same stages, respectively. CKD stages, ED, and severe ED distribution of patients are presented in Figure-1. In patients with CKD stage $\mathrm{IV} / \mathrm{V}$, severe ED frequency was higher than in other ED degrees. In patients with CKD stage III, severe ED frequency also showed this behavior (Figures 2 and 3).

Potential factors that can influence erectile function occurred in similar frequency in patients with CKD stage III and IV/V. Only body mass index was not similar between them (Table-2).

ED proportion in patients with CKD stage III was lower than in stage IV/V (Figure-4). However, proportion of severe ED did not differ between these stages (stage III versus stage IV/V).
Table 2 - Patients with chronic kidney disease on conservative treatment, stage III versus stage IV/V. Pairing among main variables that could influence erectile function.

\begin{tabular}{|c|c|c|c|c|c|}
\hline & Chron & kidnes & isease & stage) & \\
\hline Variable & & & & & P-yalues * \\
\hline varlade & & & & & \\
\hline & $\mathrm{n}$ & $\%$ & $\mathrm{n}$ & $\%$ & \\
\hline Age $\geq 50$ years & 109 & 84.5 & 101 & 87.1 & 0.566 \\
\hline Married status & 86 & 66.7 & 64 & 55.2 & 0.065 \\
\hline $\begin{array}{l}\text { Body Mass Index } \\
\geq 25\end{array}$ & 72 & 56.3 & 50 & 43.5 & 0.047 \\
\hline $\begin{array}{l}\text { Arterial } \\
\text { hypertension }\end{array}$ & 107 & 82.9 & 99 & 85.3 & 0.608 \\
\hline $\begin{array}{l}\text { Arterial } \\
\text { hypertension } \geq \\
10 \text { years }\end{array}$ & 61 & 57.5 & 51 & 53.7 & 0.582 \\
\hline Diabetes & 49 & 38.0 & 35 & 30.2 & 0.198 \\
\hline $\begin{array}{l}\text { Diabetes } \geq 10 \\
\text { years }\end{array}$ & 34 & 72.3 & 27 & 79.4 & 0.466 \\
\hline $\begin{array}{l}\text { Coronary artery } \\
\text { disease }\end{array}$ & 22 & 17.3 & 15 & 13.3 & 0.386 \\
\hline $\begin{array}{l}\text { Congestive heart } \\
\text { failure }\end{array}$ & 14 & 11.0 & 13 & 11.5 & 0.906 \\
\hline $\begin{array}{l}\text { Chronic renal } \\
\text { disease } \geq 10 \\
\text { years }\end{array}$ & 18 & 15.3 & 23 & 20.5 & 0.296 \\
\hline Active smoker b & 9 & 7.0 & 15 & 12.9 & 0.117 \\
\hline $\begin{array}{l}\text { Pack-year index } \\
\geq 20\end{array}$ & 57 & 65.5 & 51 & 64.6 & 0.897 \\
\hline Current alcohol & & & & & 0.192 \\
\hline user c & 22 & 17.1 & 13 & 11.2 & 0.156 \\
\hline $\begin{array}{l}\text { Antihypertensive } \\
\geq 4\end{array}$ & 21 & 16.3 & 22 & 19.0 & 0.581 \\
\hline Anxiolytic & 10 & 7.8 & 4 & 3.4 & 0.147 \\
\hline Antidepressant & 14 & 10.9 & 9 & 7.8 & 0.407 \\
\hline $\begin{array}{l}\text { Hematocrit } \geq \\
30 \%\end{array}$ & 122 & 95.3 & 104 & 89.7 & 0.091 \\
\hline $\begin{array}{l}\text { Cholesterol } \geq 200 \\
\mathrm{mg} / \mathrm{dL}\end{array}$ & 29 & 23.6 & 30 & 27.3 & 0.517 \\
\hline $\begin{array}{l}\text { Cholesterol HDL } \\
<40 \mathrm{mg} / \mathrm{dL}\end{array}$ & 55 & 44.4 & 57 & 52.8 & 0.200 \\
\hline $\begin{array}{l}\text { Cholesterol LDL } \\
\geq 130 \mathrm{mg} / \mathrm{dL}\end{array}$ & 27 & 22.1 & 27 & 25.5 & 0.554 \\
\hline $\begin{array}{l}\text { Triglycerides } \geq \\
150 \mathrm{mg} / \mathrm{dL}\end{array}$ & 50 & 40.0 & 41 & 37.3 & 0.668 \\
\hline
\end{tabular}

* Estimated by chi-square test; ${ }^{a}$ Classification according to Kidney Disease Outcomes Quality Initiative; $\mathbf{P}$ = Statistical significance; ${ }^{\mathbf{~}}$ Patients that smoked more than 100 cigarettes in any time of life and actually smoke; ${ }^{\mathbf{c}}$ Regular use of alcohol. 
Figure 1 - Erectile dysfunction and the proportion of severe degree in each stage.

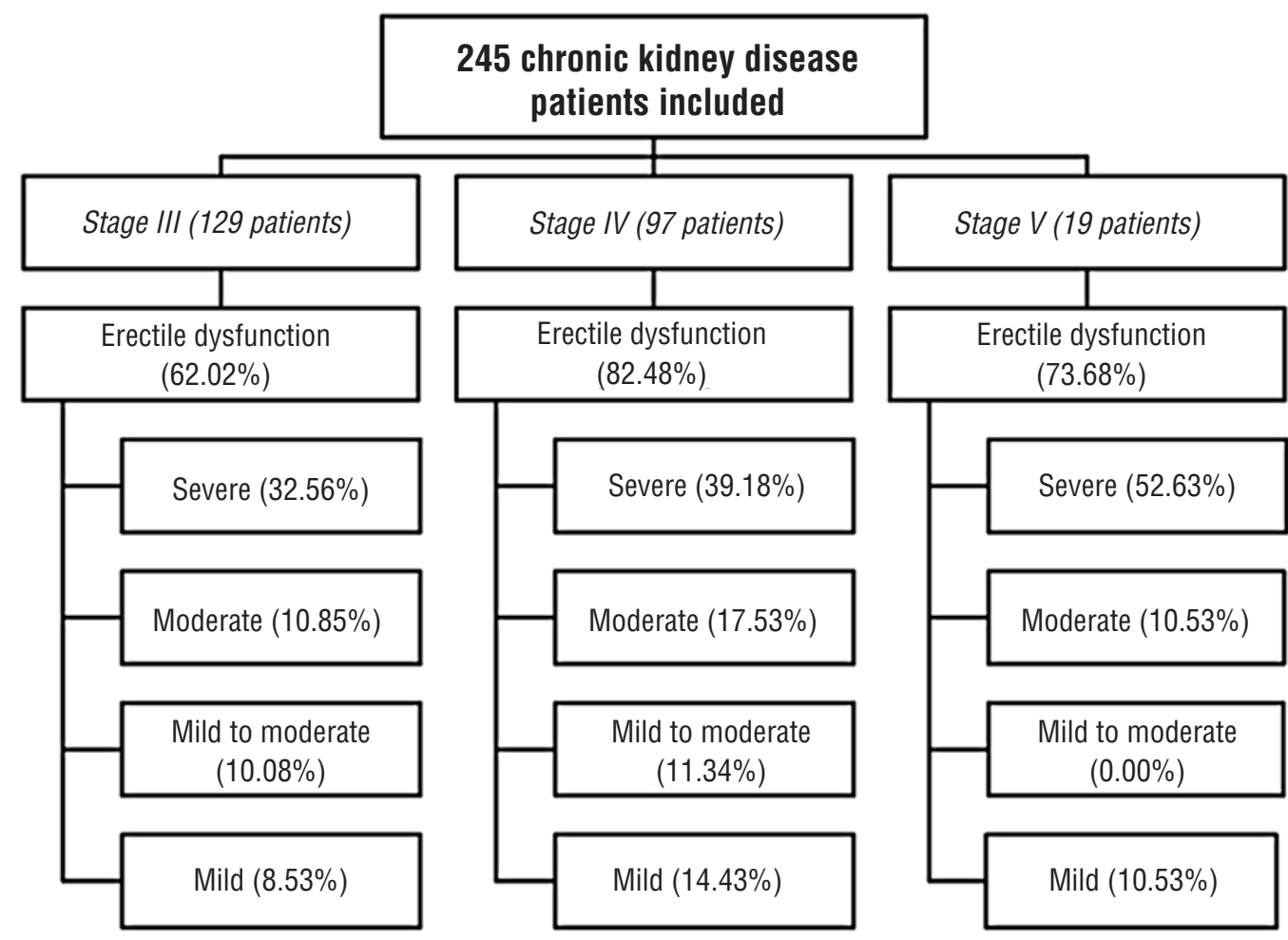

Figure 2 - Comparison of severe versus moderate, mild to moderate, and mild erectile dysfunction in patients with CKD on conservative treatment in stage III.

Estimated by chi-square test; $\mathrm{P}=$ Statistical significance; $C K D=C h r o n i c$ Kidney Disease.

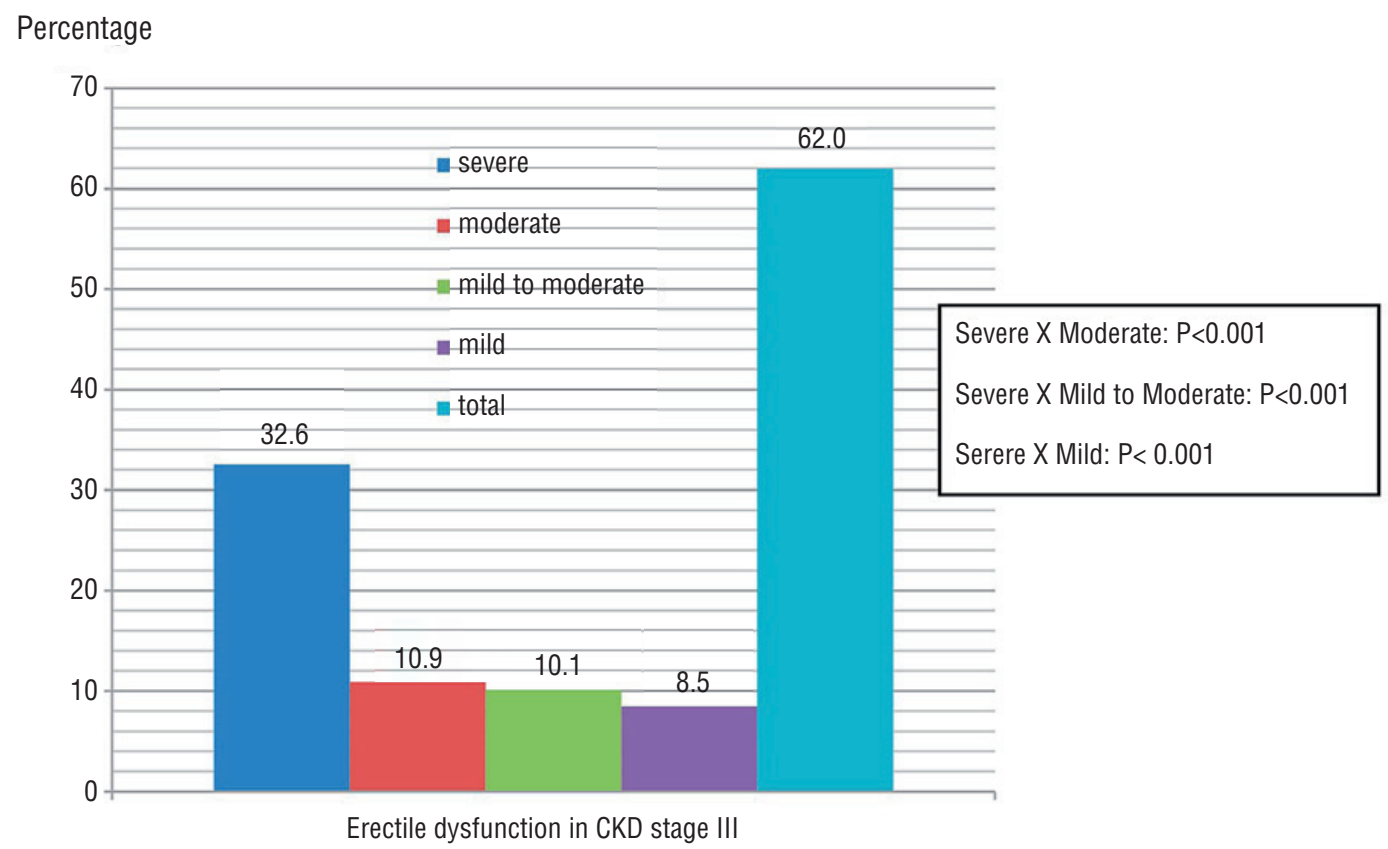


Figure 3 - Comparison of severe versus moderate, mild to moderate, and mild erectile dysfunction in patients with CKD on conservative treatment in stage IV/V.

Estimated by chi-square test; P=Statistical significance; CKD=Chronic Kidney Disease.

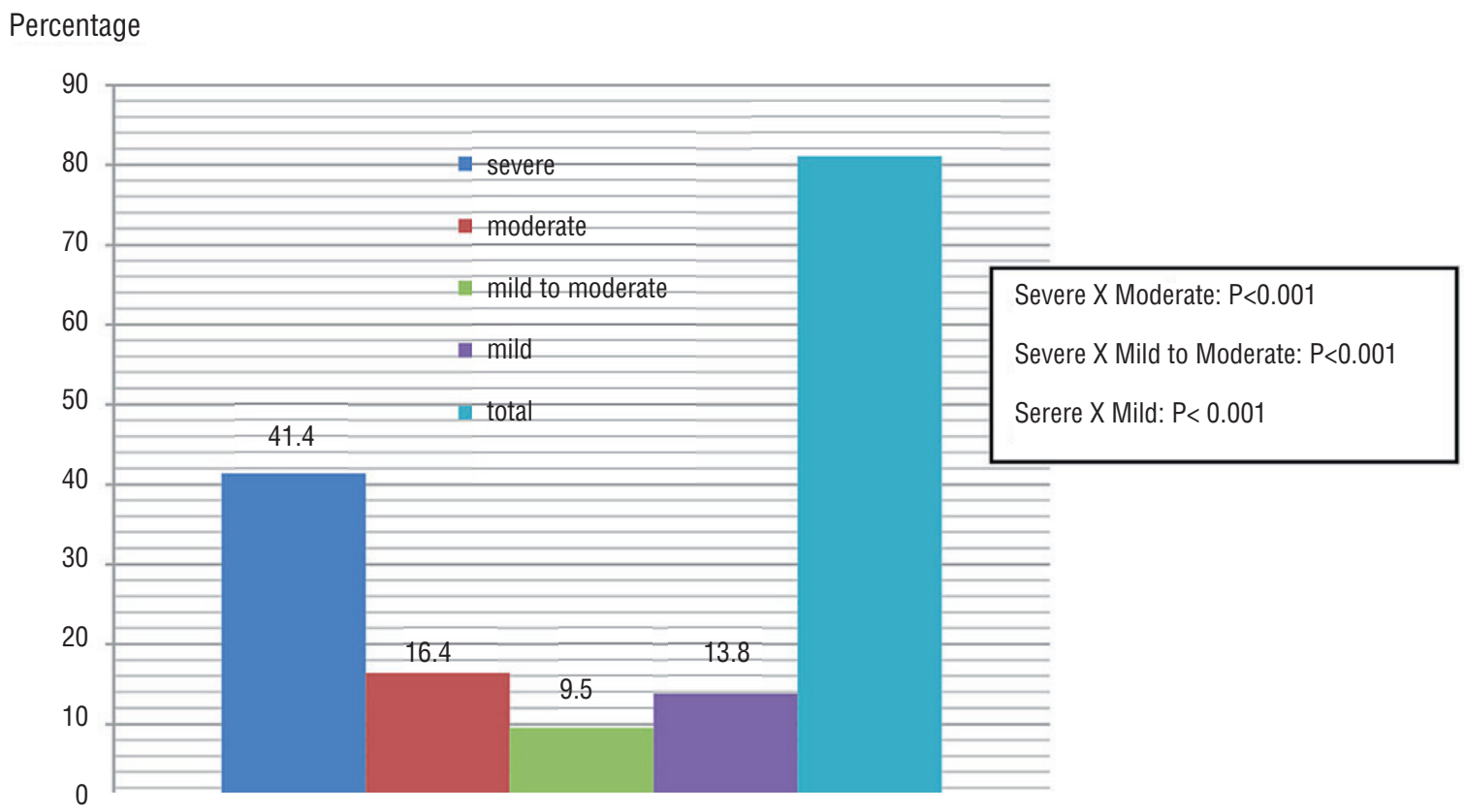

Figure 4 - Comparison of erectile dysfunction among patients with chronic kidney disease on conservative treatment in stage III versus IV/V.

Estimated by chi-square test; $\mathrm{P}=$ Statistical significance; $\mathrm{CKD}=$ Chronic Kidney Disease; IIEF=International index of erectile function.

Percentage

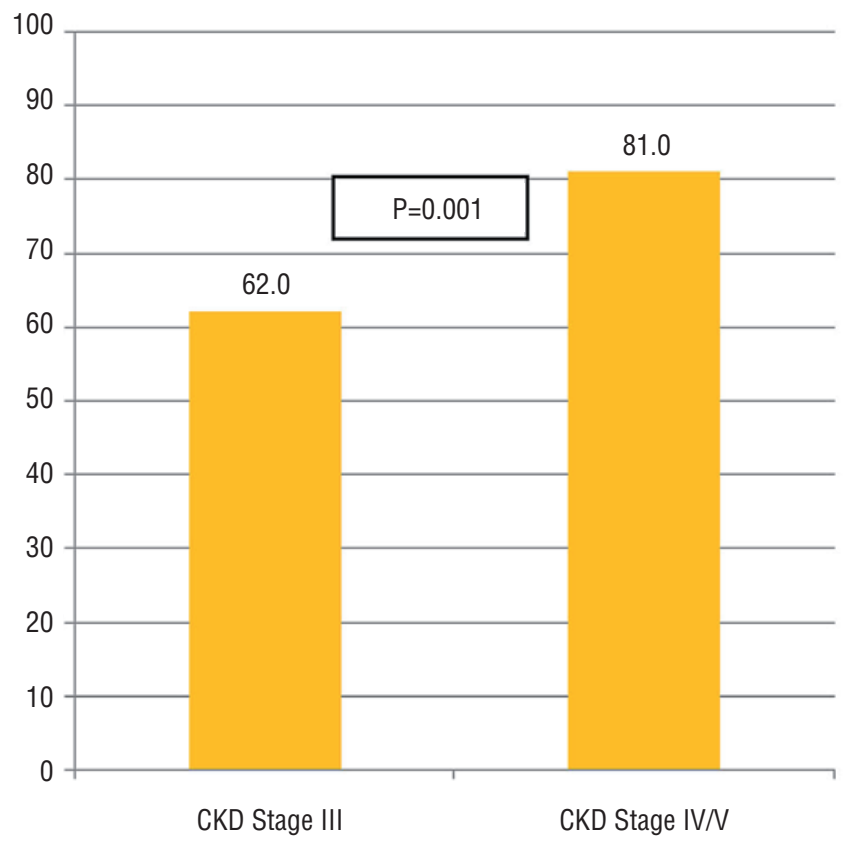

=Erectile Dysfunction according to IIEF 
The same also occurred with other ED degrees (mild, mild to moderate, and moderate) (Figure-5).

Increase of IIEF score followed the increase of GFR with a weak relationship (Figure-6).

\section{DISCUSSION}

The first reference of sexual disorder prevalence, in patients with CKDCT, estimated 9\% in

Figure 5 - Comparison of category of erectile dysfunction among patients with chronic kidney disease on conservative treatment in stage III versus IV/N.

Estimated by chi-square test; $\mathbf{P}=$ Statistical significance; $\mathbf{C K D}=$ Chronic Kidney Disease; IIEF=International index of erectile function.

Percentage

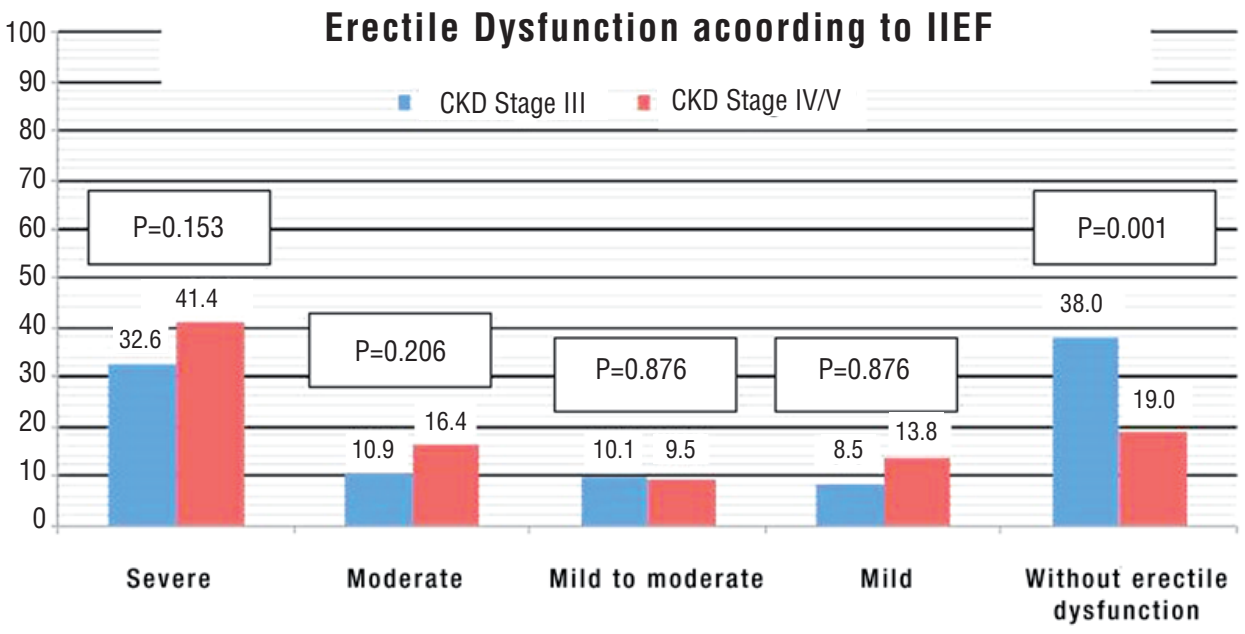

Figure 6 - Relationship of International Index of Erectile Function score and glomerular filtration rate.

$\mathbf{P}=$ Statistical significance; $\mathbf{r}=$ Pearson correlation coefficient

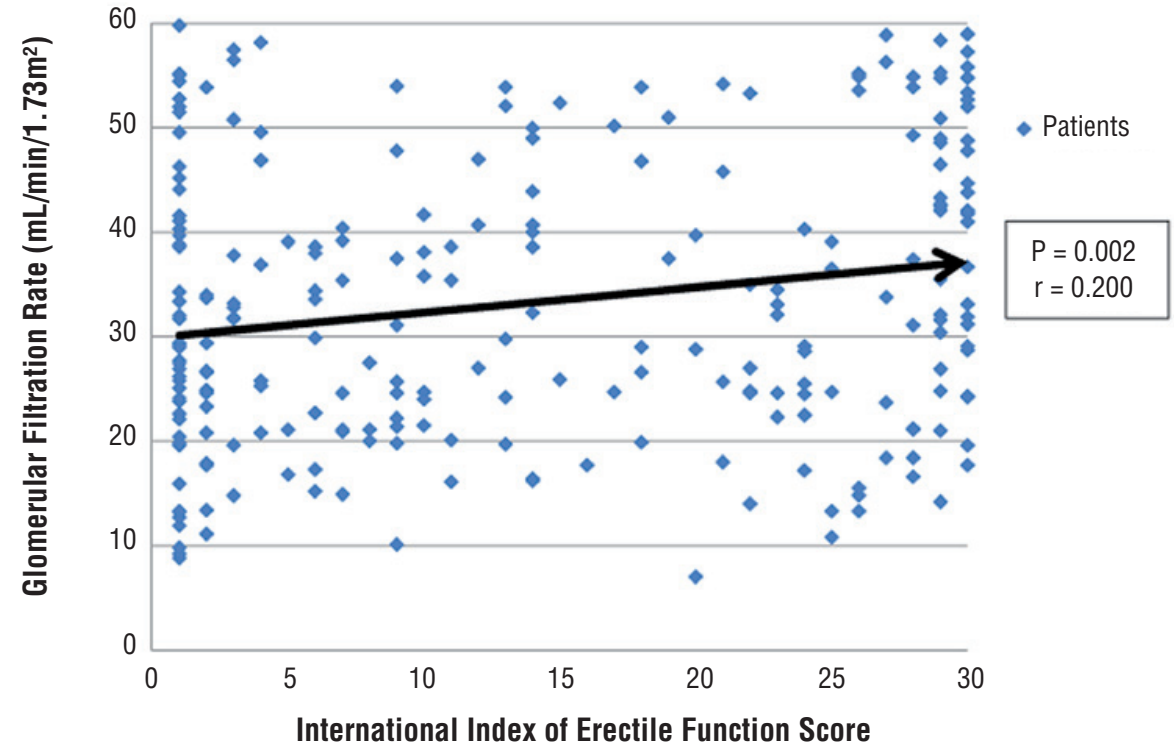


both sexes (12). Other works have evaluated erectile function in uremic patients under conservative treatment. Usually, the ED prevalence found was higher than that found in the first reference. In addition, research mostly showed severe ED more frequently than other ED classifications (mild, mild to moderate, and moderate ED) (8, 9, 11-14, 22). ED prevalence was $40 \%$ in a study of 25 male uremic patients on conservative treatment (13). Research with 53 men in CKD reported erectile disorders in $41.5 \%$ of them, before starting hemodialysis (14). One study found ED in about 30\% of all uremic patients under conservative treatment (9). ED was observed in $76.5 \%$ of 81 outpatients in a study of men with CKDCT stages III, IV and V. ED was mild, mild to moderate, moderate, and severe in $29.6 \%, 18.5 \%, 16 \%$, and $12.3 \%$ of the patients, respectively (8). ED prevalence was $84 \%$ in a research in which 26 patients had estimated GFR between 15 and 90/min/1.73m2 (8). Work that analyzed 15 pre-dialysis men with ED showed severe ED in 20\% of them (22). The present study evidenced high ED prevalence in patients with CKDCT, and to make matters worse, more than a half of patients in this work with ED and CKDCT, in stage $\mathrm{V}$, had severe ED.

Some studies registered influence of CKD stages and GFR on erectile function (10, 12, 15, 17, 18, 23). Apparent worsening or worsening of sexual function, with progression of uremia, was reported by 137 (48\%) of 287 men on hemodialysis, before starting this treatment (12). Forty-five percent of 32 male married patients on dialysis reported sexual potency decrease, after onset of renal disease (23). Direct correlation between IIEF and GFR, in outpatients with CKD, stages III and IV, was showed in preliminary results (18). Analysis of 183 men undergoing coronary angiography, to detect acute myocardial infarction, found ED correlating with lower GFR, in patients with single arterial coronary disease (15). Patients with type 2 DM had ED associated with albuminuria and lower GFR levels (17). Adult male patients with ED and chest pain, presumably of coronary origin, had a worse GFR (24). As the severity of the ED increased, a more severe decrease in the creatinine clearance occurred in male subjects with chest pain (25). Observational research involving 270 consecutive hypertensive male patients showed a significant correlation between the ED score and GFR (26). Work with a primary aim of investigating risk factors of obstructive sleep apnea demonstrated that patients with ED had lower GFR (27).

Influence of CKD stages and GFR in erectile function is not always found. ED was observed in $72.3 \%, 81.5 \%$, and $85.7 \%$ of 81 outpatients with CKD stages III, IV, and V, respectively. These ED rates were not statistically different (8). Male patients with estimated GFR between 15 and $90 \mathrm{~mL} /$ $\mathrm{min} / 1.73 \mathrm{~m} 2$ (26 patients) were compared with age-matched controls (20 patients) with estimated GFR equal or greater than $90 \mathrm{~mL} / \mathrm{min} / 1.73 \mathrm{~m} 2$. ED was found in $84 \%$ and $75 \%$ of patients, respectively. These different ED rates did not represent statistical difference (11). Patients with type 2 diabetes had ED associated with microangiopathy and diabetic retinopathy, but not with the GFR levels (16). A single-center, prospective cross-sectional study with non-diabetic male patients, stage III and IV CKD did not find ED associated with GFR (28). Male patients from a peritoneal dialysis center had daily urine volume positively associated with ED but not with the GFR (29).

The present study found lower GFR levels and/or more advanced stages of CKD associated with worse erectile function. Some works have shown that worse kidney function increases the chance and severity of sexual disorders (12, 15, 17, 18, 23). Association of CKD and ED could be explained as a consequence of injuries caused directly or indirectly by CKD. CKD can interfere directly with erectile function by decreasing penile arterial blood flow, affecting penile venous leakage due to shunts, altering penile smooth muscle function, and causing hormonal disturbances and/or neurogenic dysfunction (30). Indirectly, CKD impairs erectile function by requiring use of medications with many side effects (including ED) or linked to diabetes mellitus and/or systemic arterial hypertension, conditions that lead to endothelium dysfunction causing CKD and $\operatorname{ED}(1,3,8,9,30,31)$.

Assuming conditions resulting from CKD that directly cause damage to erectile function are magnified in the more advanced disease, it could also be assumed that the more severe the CKD is, the greater severity and frequency of ED. Another 
hypothesis is that the more serious, poorly treated, or uncontrolled diabetes and/or hypertension are, the more serious the CKD and ED resulting from them are. Therefore, the studied patients with CKD stages IV/V may had higher ED prevalence than patients with CKD stage III, because the first are more expose to directly deleterious effects of CKD in the penis or could have worse, more poorly treated or uncontrolled diabetes and/or arterial systemic hypertension than patients with CKD stage III. The present work did not evaluate severity and control of diabetes or arterial systemic hypertension, a limitation of the study.

The work has other characteristics that may have affected the results. This is an observational study. Therefore, association among studied variables can be found, but causal relationships cannot be proved among them. Non-random samples were used in this work, thus the samples may have been subject to bias. Evaluation of some variables cited as influential in erectile function (prolactin, testosterone, and zinc levels, etc.) was not performed in the present research $(32,33)$. These unevaluated variables might not have been equally distributed between patient Groups compared (stage III versus IV/V) in the study. Thus, ED prevalence in the groups could have been altered.

\section{CONCLUSIONS}

In conclusion, this study suggests that CKD progression (GFR decrease and advance in CKD stages) worsen erectile function. Hypothetically, diagnosis and treatment of ED may be anticipated with the analysis of CKD progression. Therefore, activity and sexual health may be preserved or re-assumed by CKD patients, and their quality of life may be improved.

\section{LIST OF ABBREVIATIONS}

$\mathrm{ED}=$ Erectile dysfunction

$\mathrm{CKD}=$ Chronic kidney disease

CKDCT $=$ Chronic kidney disease on conservative treatment

GFR $=$ Glomerular filtration rate

IIEF = International index of erectile function

\section{CONFLICT OF INTEREST}

None declared.

\section{REFERENCES}

1. Feldman HA, Goldstein I, Hatzichristou DG, Krane RJ, McKinlay JB. Impotence and its medical and psychosocial correlates: results of the Massachusetts Male Aging Study. J Urol. 1994;151:54-61.

2. Sánchez-Cruz JJ, Cabrera-León A, Martín-Morales A, Fernández A, Burgos R, Rejas J. Male erectile dysfunction and health-related quality of life. Eur Urol. 2003;44:245-53.

3. Brooke JC, Walter DJ, Kapoor D, Marsh H, Muraleedharan $\mathrm{V}$, Jones $\mathrm{TH}$. Testosterone deficiency and severity of erectile dysfunction are independently associated with reduced quality of life in men with type 2 diabetes. Andrology. 2014;2:205-211.

4. Mehrsai A, Mousavi S, Nikoobakht M, Khanlarpoor T, Shekarpour L, Pourmand G. Improvement of erectile dysfunction after kidney transplantation: the role of the associated factors. Urol J. 2006;3:240-4.

5. Messina LE, Claro JA, Nardozza A, Andrade E, Ortiz V, Srougi $M$. Erectile dysfunction in patients with chronic renal failure. Int Braz J Urol. 2007;33:673-8.

6. Collaborative Depression and Sexual Dysfunction in Hemodialysis Working Group, Vecchio M, Palmer S, De Berardis G, Craig J, Johnson D, Pellegrini F, et al. Prevalence and correlates of erectile dysfunction in men on chronic haemodialysis: a multinational cross-sectional study. Nephrol Dial Transplant. 2012;27:2479-88.

7. Rosas SE, Joffe M, Franklin E, Strom BL, Kotzker W, Brensinger $C$, et al. Prevalence and determinants of erectile dysfunction in hemodialysis patients. Kidney Int. 2001;59:2259-66.

8. Mesquita JF, Ramos TF, Mesquita FP, Bastos Netto JM, Bastos MG, Figueiredo AA. Prevalence of erectile dysfunction in chronic renal disease patients on conservative treatment. Clinics (Sao Paulo). 2012;67:181-3.

9. Bellinghieri G, Savica V, Santoro D. Vascular erectile dysfunction in chronic renal failure. Semin Nephrol. 2006;26:42-5.

10. Costa MR, Ponciano VC, Costa TR, de Oliveira AM, Gomes $\mathrm{CP}$, de Oliveira EC. Prevalence and factors associated with erectile dysfunction in patients with chronic kidney disease on conservative treatment. Int J Impot Res. 2017 Nov;29(6):219-224. doi: 10.1038/ijir.2017.20.

11. Esen B, Kahvecioglu S, Atay AE, Ozgen G, Okumus MM, Seyahi $\mathrm{N}$, et al. Evaluation of relationship between sexual functions, depression and quality of life in patients with chronic kidney disease at predialysis stage. Ren Fail. 2015;37:262-7. 
12. Levy NB. Sexual adjustment to maintenance hemodialysis and renal transplantation: national survey by questionnaire: preliminary report. Trans Am Soc Artif Intern Organs. 1973;19:138-43.

13. Procci WR, Goldstein DA, Adelstein J, Massry SG. Sexual dysfunction in the male patient with uremia: a reappraisal. Kidney Int. 1981;19:317-23.

14. Breza J, Reznícek J, Pribylincová V, Zvara P. [Erectile dysfunctions in patients treated with hemodialysis and kidney transplantation]. Bratisl Lek Listy. 1993;94:489-93.

15. Canat L, Canat M, Guner B, Gurbuz C, Ca kurlu T. Association between renal function, erectile function and coronary artery disease: detection with coronary angiography. Korean $\mathrm{J}$ Urol. 2015;56:76-81.

16. Hermans MP, Ahn SA, Rousseau MF. Erectile dysfunction, microangiopathy and UKPDS risk in type 2 diabetes. Diabetes Metab. 2009;35:484-9.

17. Chuang YC, Chung MS, Wang PW, Lee WC, Chen CD, Chang $\mathrm{HW}$, et al. Albuminuria is an independent risk factor of erectile dysfunction in men with type 2 diabetes. J Sex Med. 2012;9:1055-64.

18. Bellinghieri G, Santoro D, Satta E, Savica V. [Erectile dysfunction and quality of life in patients with chronic renal failure]. G Ital Nefrol. 2008;25:713-7.

19. Inker LA, Astor BC, Fox CH, Isakova T, Lash JP, Peralta CA, et al. KDOQI US commentary on the 2012 KDIGO clinical practice guideline for the evaluation and management of CKD. Am J Kidney Dis. 2014;63:713-35.

20. Cockcroft DW, Gault MH. Prediction of creatinine clearance from sérum creatinine. Nephron. 1976;16:31-41.

21. Rosen RC, Riley A, Wagner G, Osterloh IH, Kirkpatrick $J$, Mishra $A$. The international index of erectile function (IIEF): a multidimensional scale for assessment of erectile dysfunction. Urology. 1997;49:822-30.

22. Abobakr R, Alakhras A, Eyada M, Al-Yahiri Mohamed. Etiopathogenic types of erectile dysfunction in chronic kidney disease patients. J Urol. 2011;185: (Supplement 4S): e528. Abstract 1319.

23. Abram HS, Hester LR, Sheridan WF, Epstein GM. Sexual functioning in patients with chronic renal failure. J Nerv Ment Dis. 1975;160:220-6.

24. Solak Y, Akilli H, Kayrak M, Aribas A, Gaipov A, Turk S, et al. Uric acid level and erectile dysfunction in patients with coronary artery disease. J Sex Med. 2014;11:165-72.
25. Solak Y, Akilli H, Atalay H, Kayrak M, Gok H, Turk S. The association of glomerular filtration rate and erectile dysfunction with severity of coronary artery disease in patients presenting with chest pain. Int Urol Nephrol. 2010;42:765-71.

26. Artom N, Pinna G, Musso NR, Orlandini F, Malasoma $\mathrm{P}$, Uccelli $\mathrm{M}$, et al. Prevalence of erectile dysfunction in a cohort of Italian hypertensive subjects. Clin Exp Hypertens. 2016;38:143-9.

27. Omland T, Randby A, Hrubos-Strøm H, Røsjø H, Einvik G. Relation of Erectile Dysfunction to Subclinical Myocardial Injury. Am J Cardiol. 2016;118:1821-1825.

28. Toprak O, Sarı Y, Koç A, Sarı E, Kırık A. The impact of hypomagnesemia on erectile dysfunction in elderly, nondiabetic, stage 3 and 4 chronic kidney disease patients: a prospective cross-sectional study. Clin Interv Aging. 2017;12:437-44.

29. Ye H, Chen W, Cao P, Lin X, Zhang X, Xu F, et al. Prevalence of erectile dysfunction and its association with residual renal function in Chinese peritoneal dialysis patients. Int Urol Nephrol. 2015;47:383-9.

30. Platek AE, Hrynkiewicz-Szymanska A, Kotkowski M, Szymanski FM, Syska-Suminska J, Puchalski B, et al Prevalence of Erectile Dysfunction in Atrial Fibrillation Patients: A Cross-Sectional, Epidemiological Study. Pacing Clin Electrophysiol. 2016;39:28-35.

31. Shen YC, Weng SF, Wang JJ, Tien KJ. Erectile dysfunction and risk of end stage renal disease requiring dialysis: a nationwide population-based study. PLoS One.2014;9:e102055.

32. de Vries CP, Gooren LJ, Oe PL. Haemodialysis and testicular function. Int J Androl. 1984;7:97-103.

33. Dean RC, Lue TF. Physiology of penile erection and pathophysiology of erectile dysfunction. Urol Clin North Am. 2005;32:379-95. 